\title{
A Simple Atmospheric Model of Surface Heat Flux for Use in Ocean Modeling Studies
}

\author{
RichaRd KIEEMAN AND SCOTt B. POWER \\ Bureau of Meteorology Research Centre, Melbourne, Victoria, Australia
}

(Manuscript received 21 December 1993, in final form 11 May 1994)

\begin{abstract}
A simple model of the lower atmospheric layers and land/sea ice surface is described and analyzed. The model is able to depict with reasonable accuracy the global ocean heat fluxes. Due to the model's simplicity, insight into the mechanisms underlying particular heat flux responses is possible. Such an analysis is carried out for the regional Gulf Stream heat flux response (which is qualitatively correct in the model), and it is shown that atmospheric transient eddy heat transport is crucial to the modeled response. The perturbation response of the model to tropical SST anomalies is also analyzed, and it is demonstrated that the atmospheric transport processes incorporated in the model are responsible for a scale-dependent response. The magnitude of this response is shown to be significantly different to that obtained with formulations previously used by ocean modelers.
\end{abstract}

\section{Introduction}

One of the difficult issues in ocean modeling is the specification of upper surface boundary conditions. The problem stems from the unavoidable reality that the ocean is part of a coupled system involving also the atmosphere, which implies nonzero fluxes at the upper surface.

The usual practice followed by ocean modelers (e.g., see Bryan and Lewis 1979) is to specify the momentum flux and use some kind of relaxation condition on temperature for the net heat flux. The freshwater flux is often ignored in studies of the Tropics (presumably because it is assumed of minor importance there), whereas in global models either a relaxation condition is used on salinity or else a fixed flux (often derived from a relaxation run) is used. In this contribution, we focus on the net heat flux and introduce a more sophisticated model that will be useful in its own right (as part of a coupled model) but also as a means of gaining further understanding of the heat flux coupling.

The usual method for calculating net heat fluxes is due to Haney (1971) and can be expressed as

$$
Q=\kappa\left(T^{*}-T(1)\right),
$$

where $T^{*}$ is often described as an apparent air temperature $k$ describes how tightly bound the model is to $T^{*}$, and $T(1)$ is the upper-level temperature of the model. It is usual practice to use either observed air temperature (e.g., see Latif 1987) or observed sea surface temperature (SST) (e.g., see Bryan and Lewis

Corresponding author address: Dr. Richard Kleeman, BMRC, GPO Box 1289K, Melbourne, Victoria 3001 Australia.
1979 ) as an estimate of $T^{*}$ and a constant value for $\kappa$ based on the estimates of Haney (1971) or Oberhuber (1988). While the above formulation is appropriate for estimating climatological net heat fluxes, it becomes problematical when one wishes to model anomalous fluxes. This is because the "constants" $T^{*}$ and $k$ depend on air temperature and quite clearly, given the low heat capacity of the atmosphere relative to the ocean, this will be strongly influenced by SST. This point has been emphasized by Dickinson (1981) and Schopf (1983).

It is clear that if changes in air temperature $\Delta T_{\alpha}$ closely mirror SST anomalies, as one would expect from a purely local model involving a fast timescale turbulent heat transfer and a slow radiative adjustment by radiation to space, the feedback coefficient will be much smaller than the values derived by Haney (1971) and Oberhuber (1988). This follows because the turbulent flux changes will be smaller than in the case that there is no change in $T_{a}$ but a significant change in SST.

On the other hand, if nonlocal processes such as advection are also important to the near-surface temperature budget, then depending on conditions elsewhere on the ocean surface, $\Delta T_{a}$ may lie somewhere between zero [the assumption underlying the use of Eq. (1)] and $\Delta$ SST. Some reflection on this point indicates that the spatial scale of the SST anomalies and the strength of atmospheric transport will be important in determining the degree of negative feedback net heat flux (i.e., the parameter $\kappa$ ), a point made by Bretherton (1982).

Recently Luksch and Von Storch (1992) have taken this point into account by incorporating advection of atmospheric temperature by the mean circulation in a 
heat flux model used for modeling the North Pacific Ocean. In a somewhat different approach, Rahmstorf and Willebrand (1994) used a diffusion term to represent horizontal atmospheric heat transport. Such a term may be interpreted as representing transport by the transient eddies of the atmosphere.

The above nonlocality may also be important as a means of spreading ocean anomalies horizontally: a local SST change induces a local air temperature response, which is then advected by the atmosphere to another part of the ocean. A change in net heat flux at this remote site will result, which will cause a remote SST change of the same sign generally as the original SST change.

Given the importance of the restoring condition in providing a negative feedback on SST in El NiñoSouthern Oscillation (ENSO) studies [see Schopf (1983) for a sensitivity study] and also in global models in providing a potentially important positive feedback in connection with the thermohaline circulation (see Power and Kleeman 1993a,b; Zhang et al. 1993), a more sophisticated representation of surface net heat flux would seem timely. The most obvious candidate for such a model is an atmospheric general circulation model (AGCM); however, such models suffer from a number of drawbacks. First, the climatological surface net heat fluxes of such models can be quite different in character to those deduced from observations ( see Gleckler et al. 1993), and this defect can lead to serious climate drift (see Moore and Gordon 1994). Second, the models are computationally expensive and the very long integrations required to investigate decadal/interdecadel variability are therefore logistically difficult. Lowering the spatial resolution of such models to reduce the computational overhead often leads to a worsening of the first drawback (e.g., see Moore and Gordon 1994). Finally, the complexity of the AGCM can make interpretation of results difficult. In the present paper we develop an inexpensive simple model of the lower atmosphere and surface fluxes for which interpretation of results is relatively easy. The model will also serve as a useful component in a "hybrid" coupled global model currently under development. It includes specific parameterizations of horizontal heat transport associated with both transient eddies and the mean circulation.

The paper is organized as follows. The model is described in section 2. Its performance is compared to observations of net heat fluxes and surface temperature in section 3. The perturbation behavior of the model for a number of different idealized SST anomalies is considered in section 4. Finally, section 5 contains a discussion of the results presented and the implications they have for coupled modeling.

\section{Description of the model}

The model configuration is displayed in Fig. 1 and consists of a single layer model atmosphere of depth

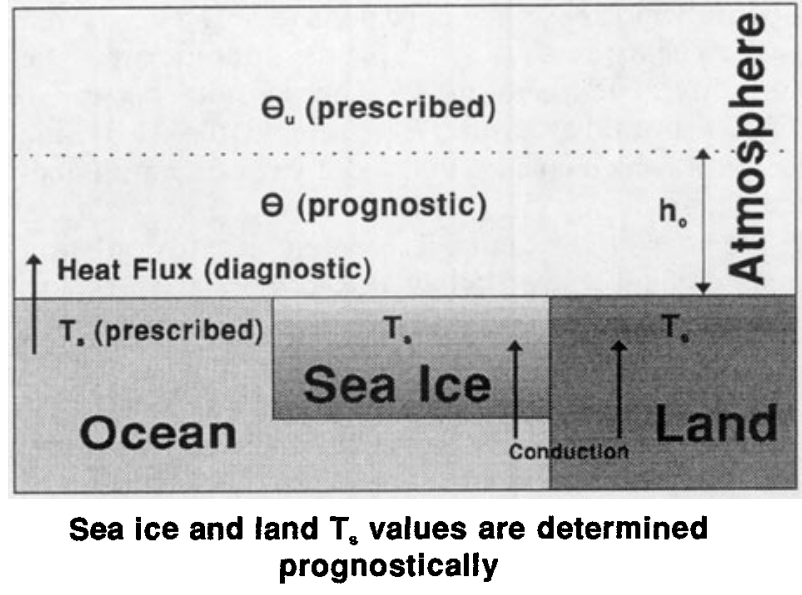

FiG. 1. A schematic of the model indicating the regions modeled and the prognostic variables used.

$h_{0}$ intended to model the near-surface part of the real atmosphere that is in turbulent contact with the surface. This includes the boundary layer as well as a portion of the cloud layer. The potential temperature of this layer $\theta$ is treated as a prognostic variable. The surface net heat flux is diagnosed and is used to prognostically determine land and sea ice temperatures. For simplicity we omit orography and assume all surfaces are at 1000 $\mathrm{mb}$. The sea ice model for the purposes of the current model will be taken to be exactly the same as land but with differing conductivity and albedo. We are thus assuming it has a fixed depth and horizontal extent. The latter is determined in the present context by taking the Reynolds (1988) SST climatology and assigning sea ice to regions with climatological SST below $-1.5^{\circ} \mathrm{C}$. Ocean surface temperatures are specified from the Reynolds (1988) SST climatology.

The net surface heat flux into the ocean is given as usual by

$$
Q=\mathrm{SW}-Q_{\text {sens }}-Q_{\mathrm{lat}}-\mathrm{LW},
$$

where $Q_{\text {sens }}$ is the upward sensible heat flux; $Q_{\text {lat }}$ is the upward latent heat flux; LW is the net upward longwave radiative heat flux; and $\mathrm{SW}$ is the net downward shortwave heat flux.

The eddy fluxes at the surface are parameterized with the usual bulk formulas:

$$
\begin{gathered}
Q_{\text {sens }}=\rho_{a} W c_{p} c_{H}\left(T_{s}-T\right) \\
Q_{\text {lat }}=r_{\text {avail }} Q_{\text {lat }}^{\text {pot }} \\
Q_{\text {lat }}^{\text {pot }}=\rho_{a} W c_{E} L_{v} H\left(q_{\text {sat }}\left(T_{s}\right)-\chi q_{\text {sat }}(T)\right),
\end{gathered}
$$

where the variables used have the following meanings and parameterization: $T$ is the near-surface temperature, $W$ is the mean climatological surface wind speed, and $c_{H}$ and $c_{E}$ are the usual dimensionless turbulent exchange coefficients. The latter are determined by use of the stability-dependent formulation outlined in 
Oberhuber (1988) and hence depend on $T_{s}-T$ as well as $W$. The expression $q_{\text {sat }}(T)$ is the saturation specific humidity at temperature $T$. The parameter $\chi$ is the relative humidity, and $H$ represents the Heaviside function, which ensures that negative evaporation does not occur.

We now discuss in detail the latent heat formulation since, as shall be seen below, this term invariably plays an important role in the surface heat flux budget.

Here $Q_{\text {lat }}^{\text {pot }}$ is the potential latent heat flux from a fully saturated surface, that is, the latent heat flux that would occur if a surface was hypothetically saturated. The factor $r_{\text {avail }}$ is the surface moisture availability, and its value is set to one over ocean and sea ice points as these surfaces are assumed to be fully saturated. Over land it is determined by assuming a steady-state "bucket" soil hydrology. Such an assumption implies that evaporation must equal precipitation unless runoff is occurring (in which case precipitation exceeds evaporation ). With such an assumption $r_{\text {avail }}$ is determined as follows. The potential evaporation defined as the evaporation occurring if $r_{\text {avail }}=1$ is compared to the climatological precipitation obtained from a 10-year integration of the Bureau of Meteorology Research Centre Atmospheric General Circulation Model (BMRC AGCM) (see Kleeman et al. 1993). If potential evaporation exceeds this value, then $r_{\text {avail }}$ is adjusted so that evaporation equals precipitation. In the case of runoff the surface is assumed saturated and $r_{\text {avail }}$ is set to unity.

The factor $\chi$ is the relative humidity of near-surface air over a saturated surface (i.e., ocean, sea ice, or runoff land points) and is assumed to be 0.8 . Such an assumption may be justified on the following grounds. First, observations from the Comprehensive OceanAtmosphere Dataset (COADS) (Fig. 2) indicate that the climatological value is quite close to 0.8 over large areas of the world's oceans. Extreme values are 0.72 and 0.88 , but the standard deviation is probably only of order 0.01 or 0.02 . Consistent with this is the observation that cloud base is very often around $950 \mathrm{mb}$ (Riehl 1979; Stull 1988), which corresponds to thermal base relative humidity close to 0.8 (lifting condensation level is relatively insensitive to near-surface air temperature and so this result is true for large variations in surface temperature). A rather remarkable result noted in the literature (see Garrett 1992) is that cloud base and the depth of the well-mixed layer are usually coincident in marine boundary layers. This suggests that, in general, there is sufficient buoyancy generated by the ocean surface to create a mixed layer up to the $950-\mathrm{mb}$ level. Calculations with a model of the humidity of this mixed layer analogous to the temperature model above, show that in the absence of any vertical export from the layer by clouds, the near-surface relative humidity will rise to at least 0.8 over most of the global oceans. The only regions where this does not occur are regions of strong surface divergence, which

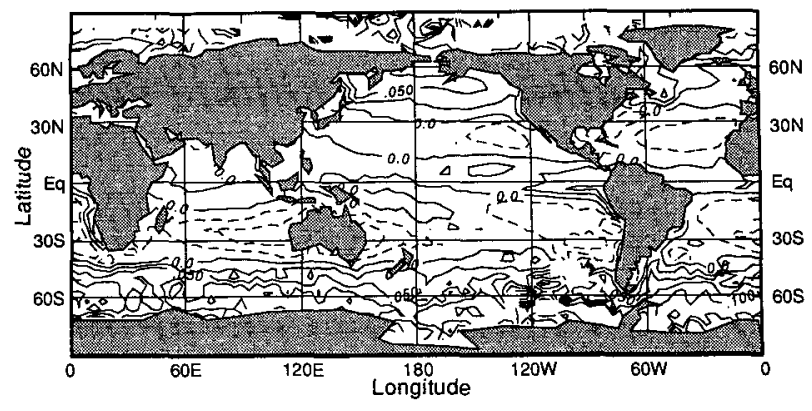

FIG. 2. The annually averaged near-surface relative humidity over the ocean derived from the COADS dataset (1950-86). The values plotted are relative to 0.8 (plotted as zero) and the contour interval is 0.025 .

are in the subtropical high pressure belt. This is because for equilibrium, surface evaporation, which is a source term for moisture, must be balanced by horizontal export of moisture, which only occurs to any appreciable extent in the above-mentioned regions. If the near-surface relative humidity reaches 0.8 , then, consistent with observations, the mixed layer will be cloud topped. This formation of clouds will clearly act to restrict moisture increase because any further increase in relative humidity will allow the mixed layer vertical eddies to easily reach lifting condensation level resulting in plentiful condensation and/or vertical export of moisture from the mixed layer.

From the above argument, we might expect that the subtropical high pressure cells are the regions where our estimate of $\chi$ is in excess of observations. This is confirmed by a careful examination of Fig. 2 . It is worth noting that the other main area of significant error is the storm track subpolar regions where, in general, relative humidity is greater than 0.8 . It may be that in such regions the ocean surface is unable to generate sufficient buoyancy to reach the $950-\mathrm{mb}$ level. This seems borne out by the fact that such regions often have a positive air-sea temperature difference (COADS data, not shown), suggesting that horizontal transport processes are stabilizing the marine boundary layer. Such an effect may also be noted in the far eastern Pacific.

With the assumption of fixed relative humidity made here, it is worth noting that our definition of potential evaporation differs from that often assumed in general circulation models. There it is defined as the evaporation that would occur if the surface was artificially saturated and other relevant variables (surface temperature and near-surface specific humidity) held fixed. Here we assume that in addition, the near-surface relative humidity reverts to its saturated value. It should be noted that the AGCM method has been subject to significant criticism in the literature (see Rowntree 1991) where it is argued that the surface temperature should be adjusted to maintain surface energy balance (the increased potential evaporation over actual evap- 
oration will result in a lower temperature). In view of the crudeness of bucket hydrologies in general (see Dickinson 1992), we consider our present parameterization adequate. As we shall see below, it leads to quite reasonable estimates of land surface temperature.
To complete the calculation of the turbulent fluxes, we require the global near-surface air temperature $T$ and the surface temperature over solid surfaces. The prognostic equation for air potential temperature $\theta=T$ has the form

$$
\frac{\partial \theta}{\partial t}+\frac{\bar{u}}{r_{E} \cos \varphi} \frac{\partial \theta}{\partial \lambda}+\frac{\bar{v}}{r_{E}} \frac{\partial \theta}{\partial \varphi}+\frac{-H(-\bar{w}) \bar{w}}{h_{0}}\left(\bar{\theta}_{e}-\theta\right)=\nabla \cdot(\nu(\varphi) \nabla \theta)+\frac{Q_{\text {sens }}}{\rho_{a} c_{\rho} h_{0}}+\mu\left(T_{s}-\theta-\Delta T_{\mathrm{rad}}\right) .
$$

(2)
(6)

(7)
The terms have the following interpretation and justification (working from left to right): the second and third terms represent horizontal advection by the mean circulation of the atmosphere. We use climatological $850-\mathrm{mb}$ winds as a proxy for the lower-layer winds $(\vec{u}$, $\bar{v})$. Strictly, we should use the averaged winds in the first $1000 \mathrm{~m}$ above the surface; however, such a climatology does not exist due to the presence of orography over land points. The particular orography used in any climatology is not usually specified, making interpolation from the given pressure levels unreliable. The flow over land needs to be adequately depicted (and not artificially blocked) since cold air flowing off the Asian and North American continents can be important to the net heat fluxes over neighboring oceans (see section 3 below). The $850-\mathrm{mb}$ winds are clear of most orography reducing this problem. Since these winds are close to the low-level geostrophic wind, their use implies a neglect of frictional flow over ocean and low-lying land points. In a sensitivity experiment, the winds were replaced in these terms by a linear interpolation of the 850 - and $1000-\mathrm{mb}$ winds appropriate to a flat surface at $1000 \mathrm{mb}$. The model experiments detailed below showed little change in the interior of ocean basins. Near coastlines, net heat fluxes were, in general, improved by the use of the 850 -mb product consistent with a better representation of the "terrain following" winds. The $850-\mathrm{mb}$ winds can therefore be regarded as an adequate approximation to the appropriate flow in the present context.

The fourth term represents vertical advection and is assumed to influence the lower layers of the atmosphere only in the case of subsidence ( $H$ is the Heaviside function ). Here, $\bar{\theta}_{u}$ is the climatological potential temperature at some fixed height above the surface (taken as $2 \times h_{0}$ ) and $\bar{w}$ is the climatological vertical velocity at $h_{0}$. We discuss the significance of this term further in sections 4 and 5 .

The fifth term represents the effect of horizontal transient eddies. In a number of zonally averaged models (Stocker et al. 1992; Harvey 1988; and Sellers 1969 ), the eddy diffusivity coefficient $\nu$ is strongly dependent on latitude and varies significantly between the three cited studies indicating uncertainty as to the coefficient's correct value. Here we set it to a constant over most of the globe. For numerical reasons only, we taper $\nu$ near the pole (this also happens to be a characteristic of $\nu$ in the aforementioned references, so it may have some physical basis). The value chosen for $\nu$ over most of the globe $\left(3.0 \times 10^{6} \mathrm{~m}^{2} \mathrm{~s}^{-1}\right)$ is not too different from the values used in the aforementioned references and is certainly within the bounds of observational uncertainty (see Gill 1982, p. 591).

The sixth term is the usual turbulent transfer from the surface with $Q_{\text {sens }}$ defined by a bulk relation (see above). Finally, the seventh term represents the radiative cooling of the boundary layer, which is parameterized as a Newtonian cooling relaxation to a radiative equilibrium temperature, which is $\Delta T_{\text {rad }}$ degrees below the surface temperature $T_{s}$. We use a value of $\mu^{-1}$ $\sim 15$ days, consistent with results from Betts and Ridgway (1989). Here $\Delta T_{\text {rad }}$ is set to $5^{\circ} \mathrm{C}$ on the basis that the radiative equilibrium profile has a lapse rate of approximately $20^{\circ} \mathrm{C} / 1000 \mathrm{~m}$ (i.e., around double the dry adiabatic lapse rate), consistent with subtropical clear sky results of Manabe and Strickler (1964).

To calculate the net surface longwave radiation flux, we require an estimate of near-surface water vapor content. This we do by interpreting Eqs. (4) and (5) as implying a value of $r_{\text {avail }} \chi q_{\text {sat }}(T)$ for near-surface specific humidity. Thus the longwave radiation is given by an empirical formula from Gill (1982):

$$
\mathrm{LW}=0.985 \sigma T_{s}^{4}\left(0.39-0.05 \sqrt{e_{a}}\right)\left(1-0.6 n_{c}^{2}\right) \text {, }
$$

where $e_{a}$ is the water vapor pressure of the nearsurface air.

Following Gill (1982), the net surface (downward) shortwave radiation is assumed to be given by

$$
\mathrm{SW}=0.72 S_{\mathrm{tao}}\left(1-\alpha_{g}\right)\left(1-0.7 n_{c}\right)
$$

where the factor 0.72 accounts for atmospheric scattering and absorption; $S_{\text {tao }}$ is the top of the atmosphere shortwave radiation and is given by a formula due to Iqbal (1983); $\alpha_{g}$ is the surface albedo (see below), and $n_{c}$ is the cloud fraction.

The ocean surface albedo is presumed, following Paltridge and Platt (1976), to be solar angle dependent:

$\alpha_{g}(\alpha)=\alpha_{s}+\left(1-\alpha_{s}\right) \exp [-18(\pi / 2-\alpha) / \pi]$, 
TABLE 1. Model parameter values.

\begin{tabular}{|c|c|c|}
\hline Parameter & Meaning & Value \\
\hline$\nu$ & Eddy diffusivity coefficient & $3.0 \times 10^{6} \mathrm{~m}^{2} \mathrm{~s}^{-1}$ \\
\hline$\mu$ & Radiative relaxation coefficient & $6.0 \times 10^{-7} \mathrm{~s}^{-1}$ \\
\hline$\Delta T_{\text {rad }}$ & Radiative equilibrium deficit & $5^{\circ} \mathrm{C}$ \\
\hline$h_{0}$ & Near-surface layer depth & $1000 \mathrm{~m}$ \\
\hline$K$ & Ice/land surface conductivity & $0.09 \mathrm{~W} \mathrm{~m}^{-20} \mathrm{C}^{-1}$ (land), $1.05 \mathrm{~W} \mathrm{~m}^{-20} \mathrm{C}^{-1}$ (ice) \\
\hline$T_{d}$ & Subsurface temperature & $-1.8^{\circ} \mathrm{C}$ (ice), $6.84^{\circ} \mathrm{C}$ (land) \\
\hline
\end{tabular}

where $\alpha$ is the angle in radians of the sun from overhead; $\alpha_{s}$ is the vertical sun surface albedo, assumed to be 0.06 . Land albedos are taken from Hummel and Reck (1979), while sea ice albedo is set at 0.7.

The surface temperature of land and sea ice points is given by

$$
\frac{\partial T_{s}}{\partial t}=-\frac{Q+C}{s_{\text {fast }}},
$$

where $s_{\text {fast }}$ is a constant chosen to ensure that solid surface temperatures adjust to equilibrium with a very rapid (hourly) timescale; $C$ is the heat conducted through the solid surface and is given by

$$
C=K\left(T_{s}-T_{d}\right),
$$

where $K$ and $T_{d}$ (the subsurface temperature) depend on the surface type (see Table 1) and follow Hart et al. (1990). In a coupled model $K$ may vary with sea ice thickness. Here we assume all sea ice has a thickness of $2 \mathrm{~m}$.

The model was numerically implemented on the Gaussian grid for global spectral models of resolution $R 21$. A leapfrog scheme with computational model filtering every 60 time steps (each of $1000 \mathrm{~s}$ ) was used.

The model requires a number of climatological datasets. The sources for these data are detailed in Table 2 . In addition, standard model parameters are listed in Table 1.

TABle 2. Model dataset sources. The National Meteorlogical Center/Climate Analysis Centre (NMC/CAC) winds are derived from the NMC final analysis. The Atmospheric Model Intercomparison Project (AMIP) AGCM products are derived from a BMRC AGCM run described in Kleeman et al. (1993). The COADS data is described in Woodruff et al. (1987), whereas the Reynolds CAC data is described in Reynolds (1988).

\begin{tabular}{lll}
\hline & \multicolumn{2}{c}{ Origin over } \\
\cline { 2 - 3 } \multicolumn{1}{c}{ Field } & \multicolumn{1}{c}{ ocean } & \multicolumn{1}{c}{ land } \\
\hline Horizontal winds & NMC/CAC & NMC/CAC \\
Vertical wind & AMIP AGCM & AMIP AGCM \\
Precipitation & not required & AMIP AGCM \\
$\begin{array}{l}\text { Cloudiness } \\
\text { Wind speed }\end{array}$ & COADS & AMIP AGCM \\
SST & COADS & AMIP AGCM \\
Lower free atmosphere & Reynolds CAC & N/A \\
temperature & & \\
\hline
\end{tabular}

The model described here is intended to be coupled to an ocean model and the net heat flux response to SST anomalies is to be the major function of the model. Clearly, the assumption that is being made in the use of the current model is that anomalies in the fields listed in Table 2 (apart from SST) are not crucial to the net heat flux response. This assumption will be tested when coupled models are constructed. In the case of ENSO SST anomalies, evidence from a general circulation model (Kleeman et al. 1993) indicates that changes in wind speed and cloudiness may play some role. For the purposes of ENSO coupled modeling it is intended to also couple the present model to a simple dynamical model that gives a good description of ENSO circulation and precipitation anomalies (see Kleeman 1991). These two fields can then be used to parameterize wind speed and cloudiness changes in a reasonably straightforward fashion. These issues are discussed further in section 5 .

\section{Model performance and sensitivity}

The model was spun up from a state in which air temperature was set equal to surface temperature; land temperature was set equal to $10^{\circ} \mathrm{C}$, and sea ice to $-20^{\circ} \mathrm{C}$. Results from the first year of the model run were discarded and those from the second year analyzed. Results from the third year were found to differ little from those of the second.

The annually averaged net heat flux is depicted in Fig. 3 along with the observations from Oberhuber (1988). The observed fields have been interpolated from a $2^{\circ} \times 2^{\circ}$ grid onto the coarser model grid. This has the effect of reducing peak values of fluxes. Reasonable agreement can be seen for all dominant features from the observations: the large fluxes out of the ocean over the Kuroshio and Gulf Stream are depicted (although the magnitudes are a little underestimated). The model Gulf Stream response has qualitatively the same spatial structure as the observations and is discussed further below.

The regions of strong downward flux in the Tropics and subtropics are reasonably described by the model. The equatorial Atlantic and Pacific peaks are well positioned albeit somewhat underestimated in the model; the downward flux regions off the west coasts of both the American and African continents are present in 

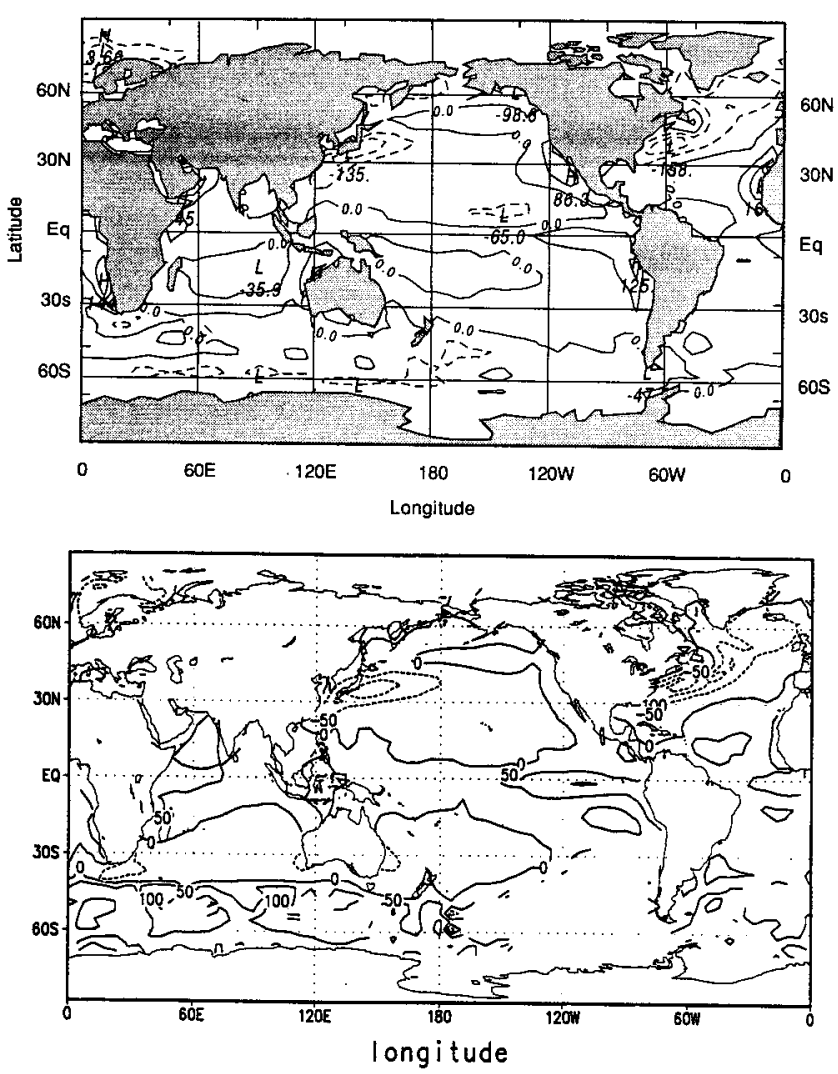

FIG. 3. (a) The modeled annually averaged surface net heat flux (defined as the total net heat flux passing into the ocean). (b) The observational estimates of annually averaged surface net heat flux derived from Oberhuber (1988). Contour interval in both cases is 25 $\mathrm{W} \mathrm{m}^{-2}$, and positive values indicate flux into the ocean.

both observations and model. It is worth noting that the model estimates (particularly off Africa) are significantly greater than Oberhuber's, but at least in the Atlantic are not greatly in excess of the estimates of Bunker (1980) whose map shows fluxes into the ocean of $100-150 \mathrm{~W} \mathrm{~m}^{-2}$ off the Saharan coast and peak values in excess of $150 \mathrm{~W} \mathrm{~m}^{-2}$ off the Kalaharan Desert in Namibia. Despite this, there probably is a model error off the West African coast as calculations with a moisture model (described in the previous section) indicate that relative humidities should be less than 0.8 in the region because of the strong drying influence of the Saharan region. A decrease in relative humidity in this region will obviously enhance evaporation and hence reduce the modeled net heat flux into the ocean.

It is interesting to note that the model predicts large fluxes out of the ocean off the sea ice margins in both Northern and Southern Hemispheres. The Oberhuber atlas does not adequately cover such regions; however, evidence presented by Holland et al. (1993) (among others) supports such a feature, at least in the North Atlantic.

The model predicts land temperatures via Eqs. (2), (10), and (11) and indirectly via the latent heat pa- rameterization, so it is of interest to compare these to observations particularly as atmospheric transport processes from land to ocean are thought important for fluxes particularly off Northern Hemisphere east coasts.

A direct comparison with observations is not really appropriate because of the absence of topography in the model, so instead a comparison with the Climate Analysis Centre (CAC) $1000-\mathrm{mb}$ temperature is presented in Fig. 4. The general character and even magnitudes are reasonably well depicted. The global maximum over the Arabian peninsula is depicted as is the general $20^{\circ} \mathrm{N}$ Saharan peak in temperature. The Arctic temperatures are a little low, but the spatial pattern is qualitatively correct. The general zonal decline in Northern Hemisphere continental temperatures from west to east is depicted. The Antarctic temperatures are a little difficult to evaluate given the large topographic dome in the region (the observed values are subsurface extrapolations). Nevertheless, the general character with an east Antarctic minimum is reproduced.

We now examine in detail the causes of a particular regional net heat flux response. We choose the Gulf Stream response off the eastern coast of North America because it has a particularly dominant role in the Northern Hemisphere and is relevant to studies of variability in the North Atlantic. Depicted in Fig. 5 are four components of the net heat flux for the North Atlantic as well as the total flux. It is quite clear that the latent heat flux is primarily responsible for the response with sensible heat adding perhaps $40 \%$ to the total response. Both depend on two relevant quantities,
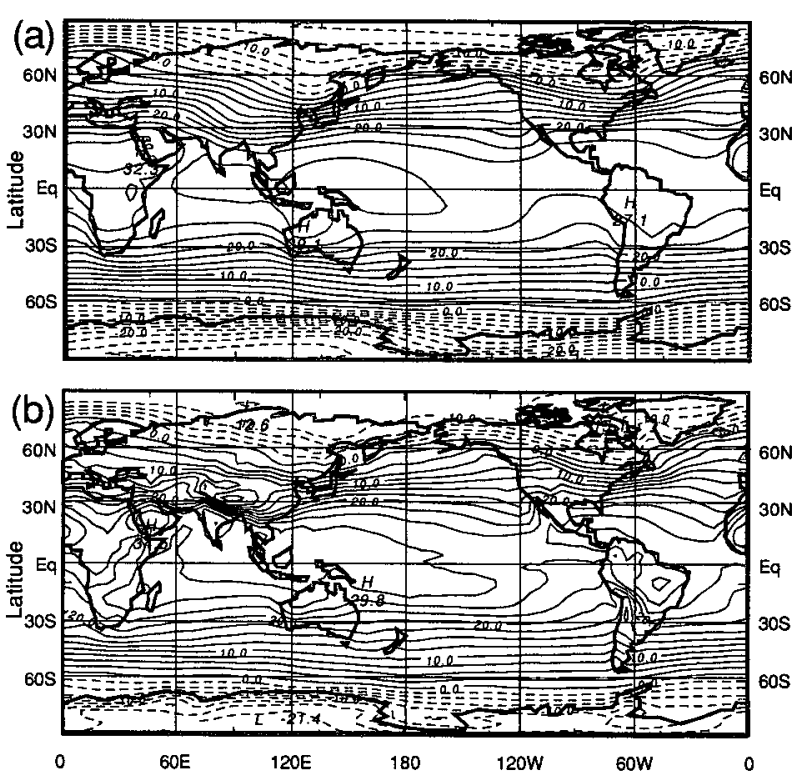

FIG. 4. (a) The modeled annually averaged surface layer air temperature. (b) The annually averaged $1000-\mathrm{mb}$ temperature derived from CAC Washington. Contour interval in both cases is $2.5^{\circ} \mathrm{C}$. 

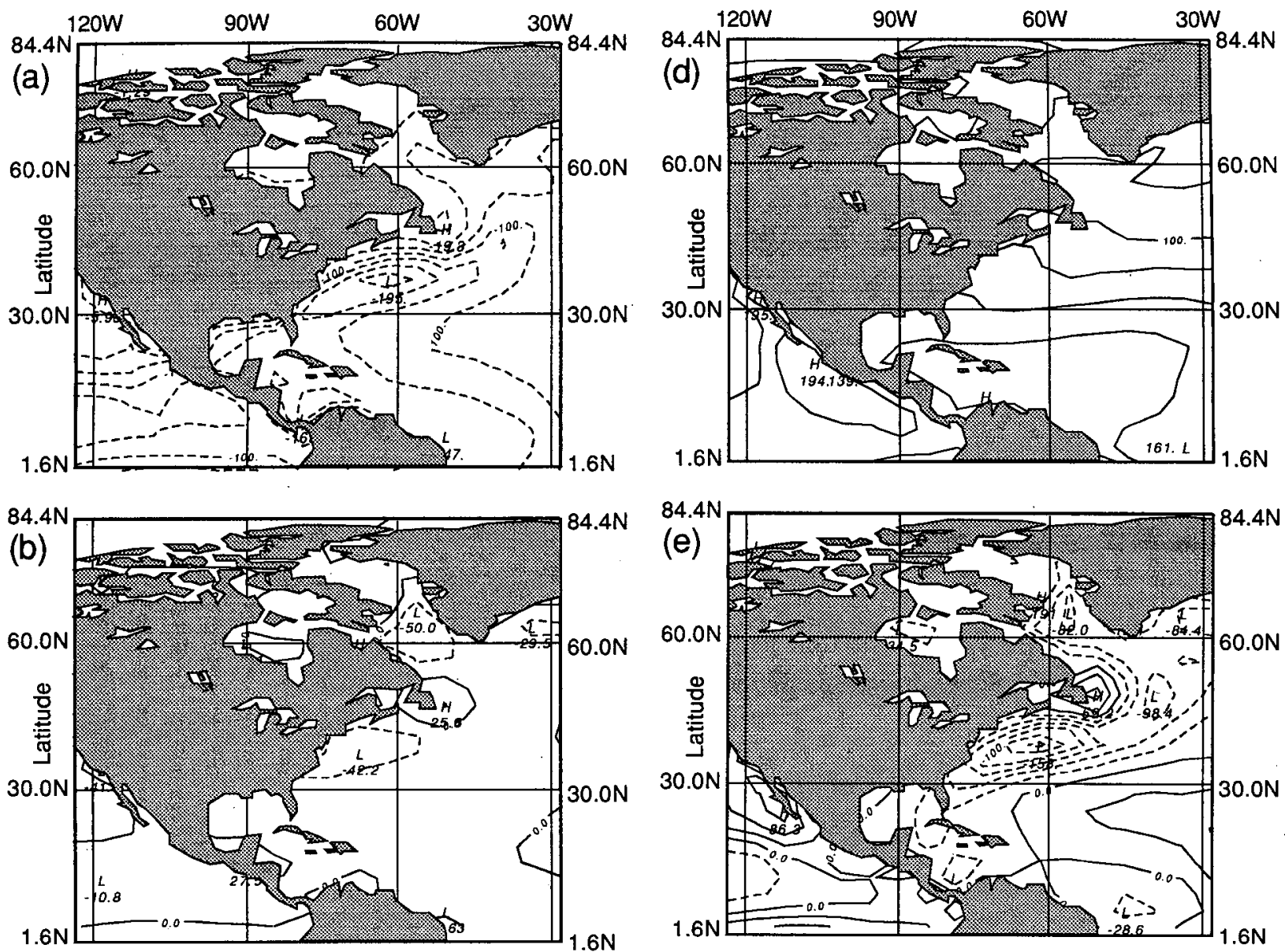

$84.4 \mathrm{~N}$
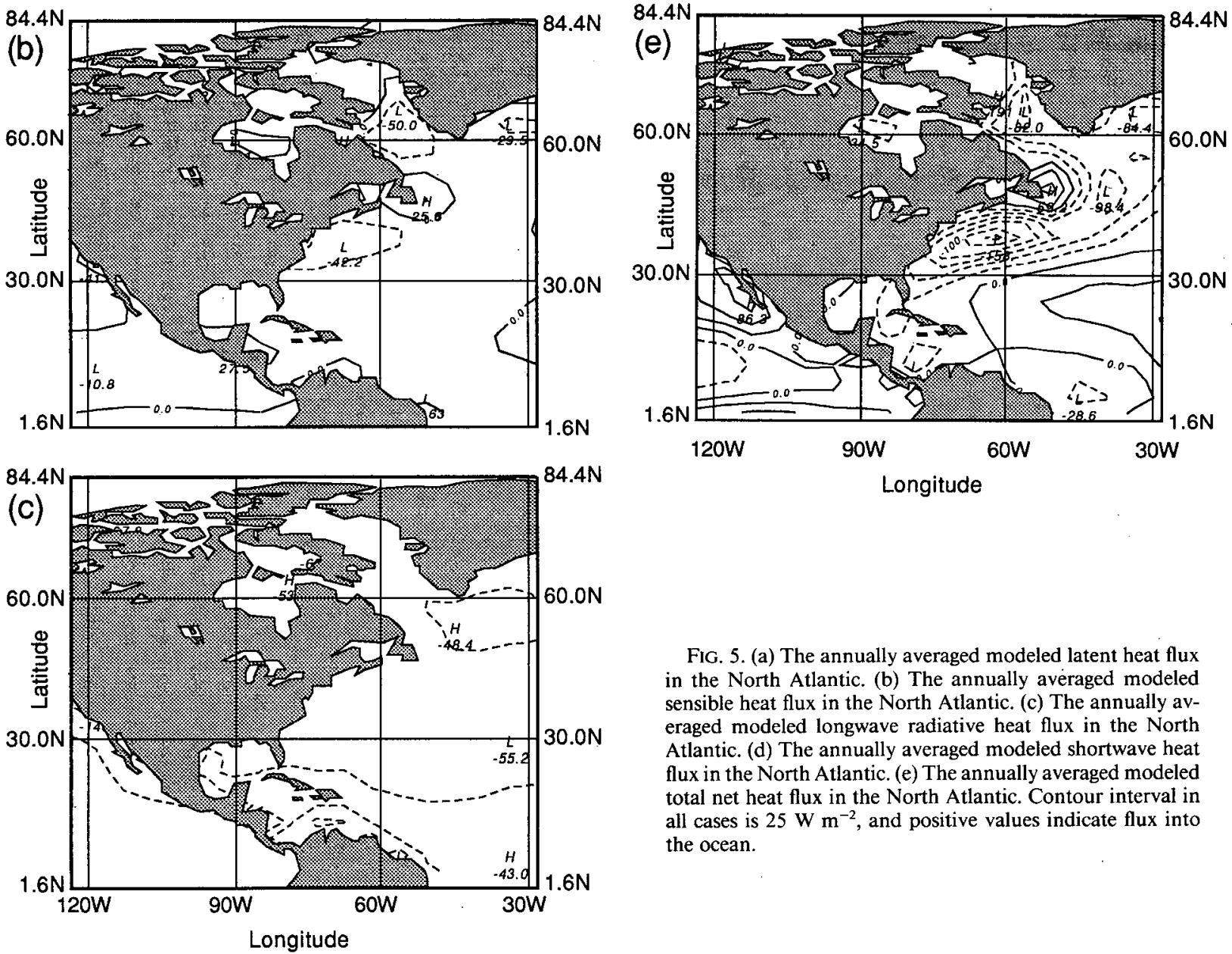

FIG. 5. (a) The annually averaged modeled latent heat flux in the North Atlantic. (b) The annually averaged modeled sensible heat flux in the North Atlantic. (c) The annually averaged modeled longwave radiative heat flux in the North Atlantic. (d) The annually averaged modeled shortwave heat flux in the North Atlantic. (e) The annually averaged modeled total net heat flux in the North Atlantic. Contour interval in all cases is $25 \mathrm{~W} \mathrm{~m}^{-2}$, and positive values indicate flux into the ocean.

the sea-air temperature difference and the wind speed. Enhancement of both quantities leads to increases in both turbulent fluxes because of the form of the bulk relations and because they increase the instability of the boundary layer and thus modify the dimensionless exchange coefficients $c_{H}$ and $c_{E}$. The wind speed (not

shown) is enhanced over most of the North Atlantic (compared to the zonal mean) and thus the smallerscale features of the response must be due to $T_{s}-T$, which clearly shows the required pattern (Fig. 6). It is of interest to further examine the causes of this field by decomposing the air temperature budget into its 


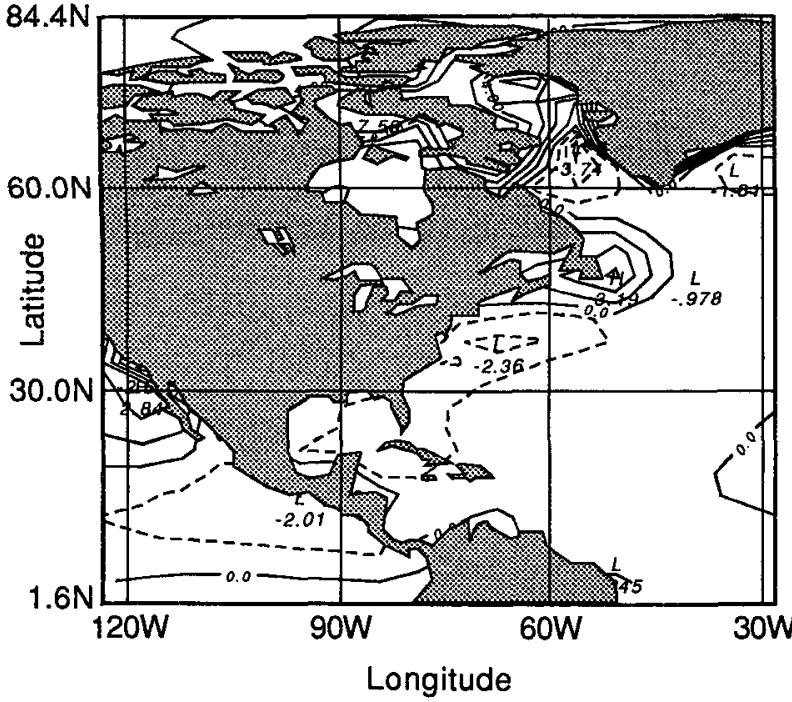

Fig. 6. (a) The annually averaged modeled air minus surface temperature in the North Atlantic. Contour interval is $1.0^{\circ} \mathrm{C}$.

various components (Fig. 7). The dominant balance here is between horizontal advection, eddy diffusion, and sensible heat transfer. Clearly, the latter term is purely restorative and acts to simply eliminate air-sea temperature differences. Examination shows that the eddy diffusivity has the required pattern to explain most of the $T_{s}-T$ pattern and hence the total net heat flux response in the region. Given the qualitative agreement of the total net heat flux with the observations, this is an encouraging result regarding the parameterization of horizontal eddy transport of heat and provides support for the use of the heat flux parameterization described by Rahmstorf and Willebrand (1994) (see section 1). Note, however, that horizontal advection is still a significant influence on the air temperature.

We turn now to the depiction of the seasonal variations in net heat flux. Figure 8 shows the modeled and observed total net heat fluxes for January and July. The January model pattern shows qualitatively good agreement with the observations: The extremely high fluxes out of the ocean over the Kuroshio and Gulf Stream are depicted, albeit at a somewhat reduced level compared to observations in the latter case. The tropical Pacific and Atlantic Ocean patterns are quite well depicted with the sharp gradient between net flux out to net flux into the ocean being at approximately the same location $\left(0^{\circ}-20^{\circ} \mathrm{N}\right)$. The large fluxes into the ocean around the Australian continent in the model disagree with the Oberhuber estimates. This may be due either to model deficiency here or the lack of horizontal resolution in the Oberhuber analysis [the large fluxes have very small horizontal scales and as we saw above, there is sometimes disagreement in coastal regions between Oberhuber and Bunker (1980) at least in the Atlantic].
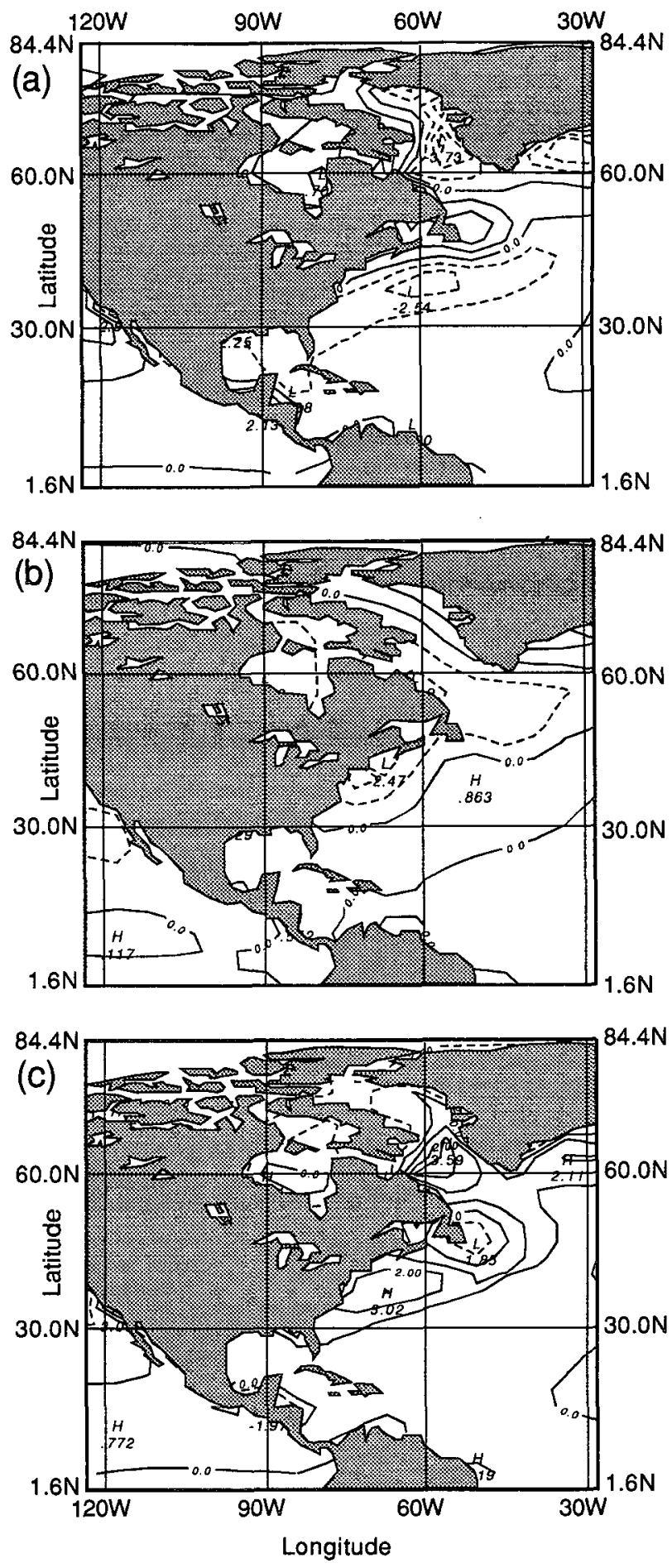

FIG. 7. (a) The annually averaged modeled air temperature tendency due to eddy diffusion in the North Atlantic. (b) The annually averaged modeled air temperature tendency due to horizontal advection in the North Atlantic. (c) The annually averaged modeled air temperature tendency due to sensible heating in the North Atlantic. Contour interval in both cases is $1.0^{\circ} \mathrm{C} \mathrm{day}{ }^{-1}$. 
The July fluxes again show reasonable qualitative agreement in most regions. The sizable fluxes into the ocean just to the north of the Kuroshio and Gulf Stream are well positioned in the model as are the deep tropical fluxes in the Pacific and Atlantic Oceans. The fluxes out of the ocean in the South Pacific and south Indian Oceans are smaller in the model relative to Oberhuber. This is due to a smaller model latent heat flux in these regions and is probably a model deficiency. The model assumption of 0.8 for relative humidity in these regions is an overestimate (cf. Fig. 2) and hence might underlie at least part of the discrepancy. As with the annual pattern, the flux into the Atlantic Ocean off the Saharan coast of Africa is in excess of Oberhuber's estimates. As discussed previously, this may be due both to model error and lack of resolution in the Oberhuber estimates near the coast.

The depiction of the seasonal cycle in a region of particular interest was also examined. In Fig. 8e, the midlatitude North Atlantic $\left(30^{\circ}-60^{\circ} \mathrm{N}, 30^{\circ}-90^{\circ} \mathrm{W}\right)$ modeled and observed net heat flux is depicted. As can be seen, there is reasonable agreement between the two with the modeled response tending to slightly underestimate the solstitial extrema and show a small phase lag during summer.

The two major parameters with a degree of uncertainty attached to them in the model are the eddy diffusivity coefficient $\nu$ and the mixing scale height $h_{0}$. Two experiments were conducted to test the sensitivity of model results to values of these parameters: $\nu$ and $h_{0}$ were halved in value separately. In broad terms the sensitivity of the fluxes was similar in both experiments: the Kuroshio and Gulf Stream peak fluxes were reduced by around $30 \%-40 \%$ and the global temperatures extremes in the Sahara, Arctic, and Antarctic were accentuated by $2^{\circ}, 5^{\circ}$, and $10^{\circ} \mathrm{C}$, respectively. There was little change in the deep tropical fluxes.

\section{Perturbation behavior}

In this section we examine the anomalous net heat flux response to imposed SST anomalies and compare the implied feedbacks obtained with the negative feedbacks previously used in ocean modeling (Haney 1971; Schopf 1983; Philander and Siegal 1985). We shall concentrate our attention here on ENSO-type SST anomalies.

In the first ("standard") experiment a Gaussian SST anomaly centered on $0^{\circ}, 110^{\circ} \mathrm{W}$ was applied. The $e$ folding decay length was set at $40^{\circ}$ in the zonal direction and $10^{\circ}$ in the meridional direction (see Fig. 9a).

The net heat flux response to this anomaly can be seen in Fig. $9 \mathrm{~b}$ and shows a rather interesting pattern: In the central peak of the anomaly, the expected negative feedback is seen but two smaller off-equatorial positive feedback lobes exist displaced to the west of the anomaly.

The various components of the flux can be seen in Figs. 9c-e (latent, sensible, and longwave, respectively: the shortwave is unchanged because cloudiness changes are not incorporated), where it is clear that the latent and, to a lesser degree, sensible changes are primarily responsible for the total response. The small longwave changes, which tend to act as a positive feedback, are due to the increased blanketing effect of the increased atmospheric humidity. The displacement of the response toward regions of higher total SST (northward and westward) are a result of the nonlinear nature of the Clausius-Clapeyron relation for humidity.

The dominant turbulent flux changes are driven by the change in $T_{s}-T$ (Fig. 10), whose pattern clearly corresponds with these changes. In the peak SST region the air temperature $T$ does not adjust to the same extent as SST, whereas in the positive feedback regions the air temperature changes exceed SST changes. This situation indicates the importance of the transport terms in the air temperature equation, and these can be seen in Figs. 1 la-c (eddy diffusion, horizontal, and vertical advection, respectively). In the present situation, it is clear that eddy diffusion is primarily responsible for ensuring that the air temperature change does not keep up with the SST change in the peak anomaly equatorial region. In other words, the eddies act to transport out the extra heat put locally into the atmosphere by sensible heat transfer. The horizontal advection acts to transport heat downstream (i.e., westward in the trades), and it seems to be the major cause of the westward displacement of the positive feedback lobes mentioned previously. It also (along with the vertical advection ) seems responsible for the eastward shift in the negative feedback because of the transport of zero anomaly air into the peak SST regions from the southeast. The positive feedback lobes are a result of the export of heat from the peak anomaly regions to regions where the SST anomaly is much reduced. This is achieved primarily by horizontal advection and eddy diffusion.

We now examine the dependence of the negative feedback on the scale of the SST anomaly. This is done by varying the meridional $e$-folding decay length from $2^{\circ}$ to $15^{\circ}$ and calculating the ratio of the anomalous net heat flux response to the SST anomaly for the equatorial eastern Pacific $\left(150^{\circ}-90^{\circ} \mathrm{W}\right)$. The results can be seen in Fig. 12 and demonstrate, as argued by Bretherton (1982), a sizable inverse relation between feedback and scale. For meridional scales typical of ENSO $\left(10^{\circ}-15^{\circ}\right)$ a value of around $14 \mathrm{~W} \mathrm{~m}^{-2}$ $\left({ }^{\circ} \mathrm{C}\right)^{-1}$ is indicated, which compares well with observational estimates (Kleeman et al. 1993). It is interesting to contrast these values with those presented by Oberhuber (1988) and Haney (1971) where values of around $30-40 \mathrm{~W} \mathrm{~m}^{-2}\left({ }^{\circ} \mathrm{C}\right)^{-1}$ are computed. As stated in the introduction, this is because these estimates assume no air temperature anomaly. If the above standard experiment is repeated with the air temperature held fixed at its climatological value, then a feedback of $34 \mathrm{~W} \mathrm{~m}^{-2}\left({ }^{\circ} \mathrm{C}\right)^{-1}$ results, which is more 

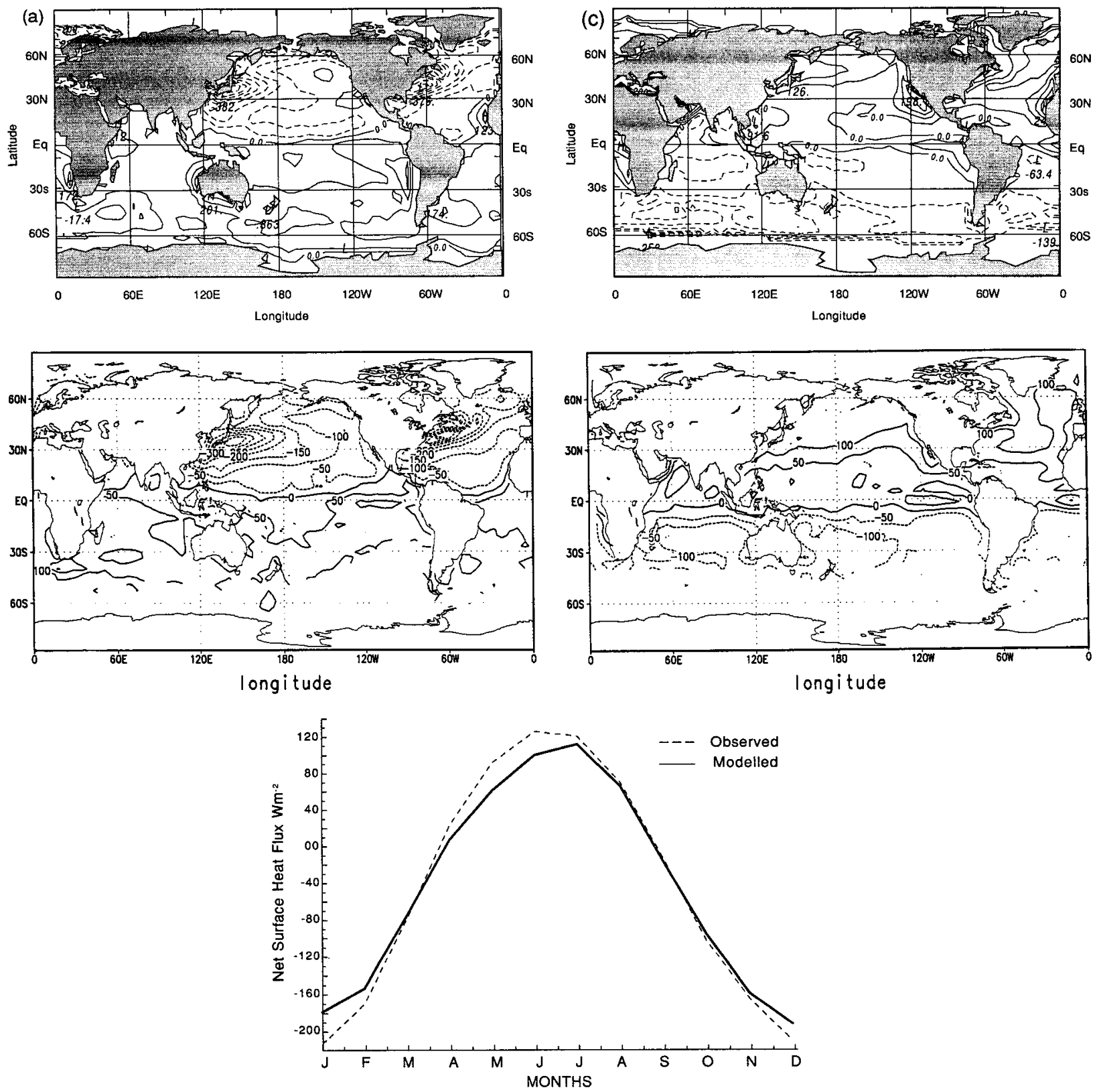

FIG. 8. (a) The modeled January surface net heat flux. (b) The observational estimates of January surface net heat flux derived from Oberhuber (1988). (c) The modeled July surface net heat flux. (d) The observational estimates of July surface net heat flux derived from Oberhuber (1988). Contour interval is $50 \mathrm{~W} \mathrm{~m}^{-2}$, and positive values indicate flux into the ocean. (e) The observed (Oberhuber) and modeled seasonally varying surface net heat flux for the North Atlantic ocean region $\left(30^{\circ}-60^{\circ} \mathrm{N}, 30^{\circ}-90^{\circ} \mathrm{W}\right)$.

in agreement with Oberhuber's eastern Pacific values. It is also worth comparing this feedback with one resulting from the Philander and Siegal (1985) method, which assumes $T_{s}-T=1.5^{\circ} \mathrm{C}$ (these authors assume, as here, a near-surface relative humidity of 0.8 ); the model was run under this prescription with and without the standard anomaly. The feedback was computed as $5 \mathrm{~W} \mathrm{~m}^{-2}\left({ }^{\circ} \mathrm{C}\right)^{-1}$. In other words, a much smaller feedback than those seen here. These consid- erations have clear implications for tropical ocean modeling.

\section{Discussion and summary}

A net heat flux model useful for ocean modeling studies has been detailed. It should serve as a generalization of previous formulations, which have either assumed a fixed air temperature in response to SST 
(a)

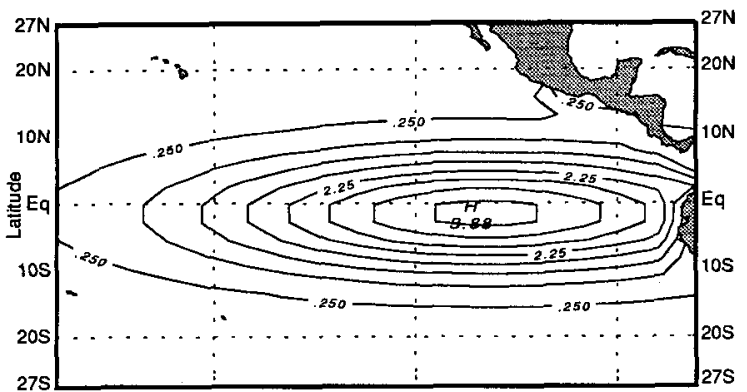

(b)

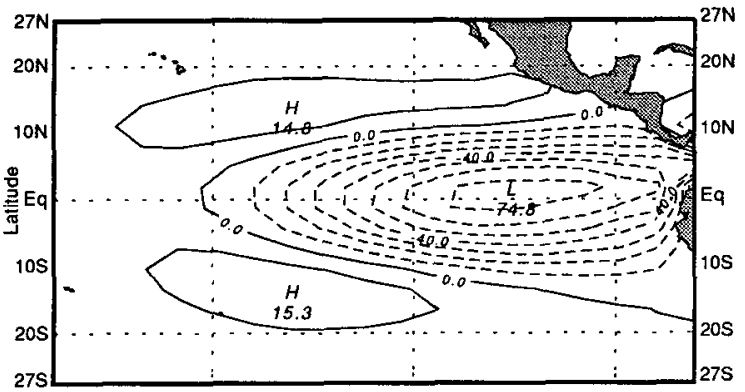

(c)

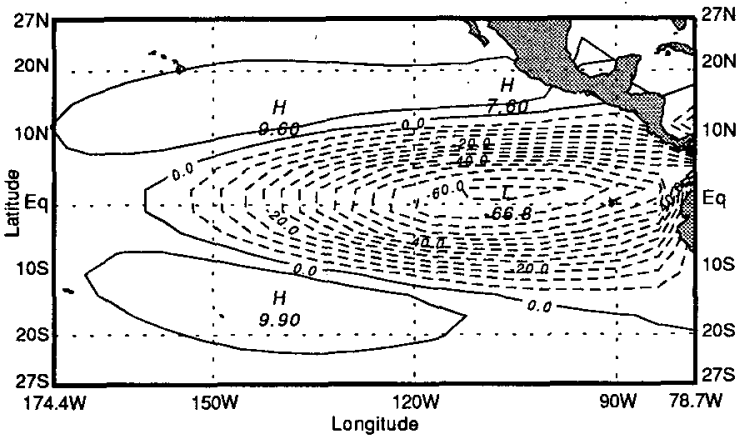

anomalies (Haney 1971; and Oberhuber 1988) or a constant air-sea temperature difference (Schopf 1983; Philander and Siegal 1985). The net heat flux negative feedbacks to SST anomalies produced by the model

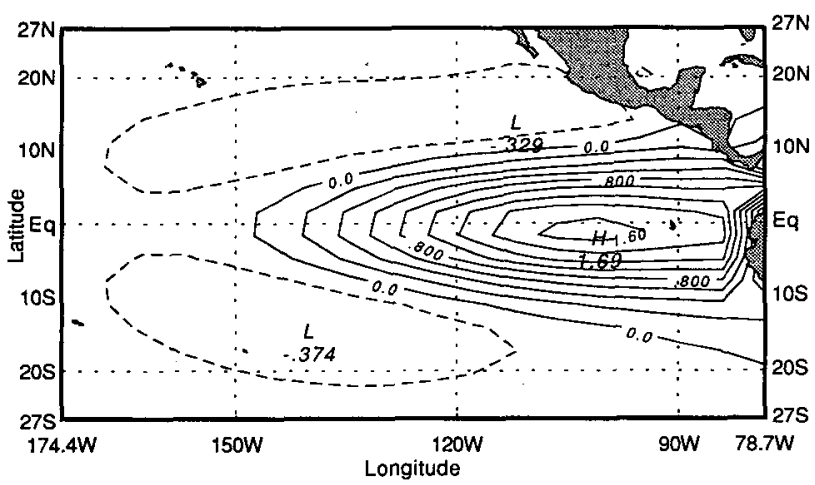

Fig. 10. The change in surface minus air temperature in response to the SST anomaly depicted in Fig. 9a. Contour interval is $0.2^{\circ} \mathrm{C}$. (d)

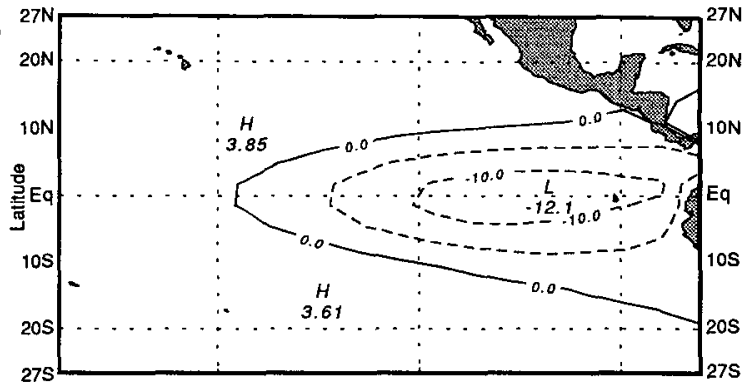

(e)

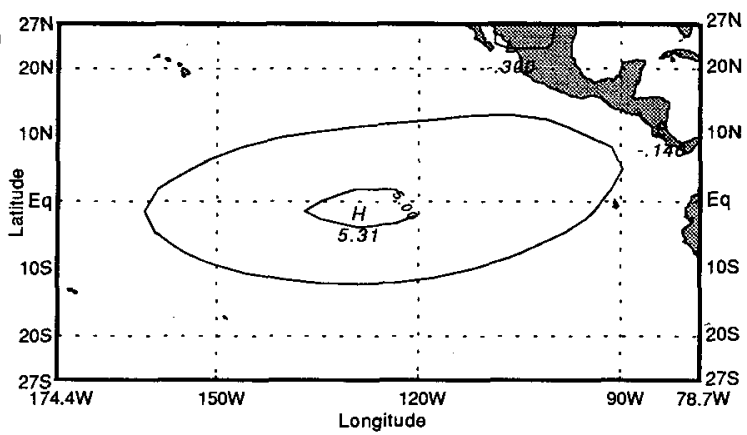

FIG. 9. (a) The SST anomaly used to force the model in perturbation experiments. Contour interval is $0.5^{\circ} \mathrm{C}$. (b) The anomalous total net heat flux response to the SST anomaly in panel a. Contour interval is $10 \mathrm{~W} \mathrm{~m}^{-2}$. (c) The anomalous latent heat flux response to the SST anomaly in panel a. Contour interval is $5 \mathrm{~W} \mathrm{~m}^{-2}$. (d) The anomalous sensible heat flux response to the SST anomaly in panel a. Contour interval is $5 \mathrm{~W} \mathrm{~m}^{-2}$. (e) The anomalous longwave heat flux response to the SST anomaly in panel a. Contour interval is $2.5 \mathrm{~W} \mathrm{~m}^{-2}$. are strongly scale dependent and are intermediate in magnitude between those produced by the previous formulations. The reason for this is quite simple: The model relies on its atmospheric transport processes (eddy diffusion and advection) to ensure that air temperature anomalies are smaller than SST anomalies. On the other hand, sensible heat transfer into the atmosphere from the surface ensures that the air temperature anomalies generally are nonzero. The scale dependence is simply a consequence of the greater efficiency of transport processes for smaller-scale anomalies (as discussed by Bretherton 1982): the air temperature tends to be set more by its large-scale environment than by local transfer from the surface. The present model predicts surface temperature for land and sea ice surfaces, and these agree reasonably well with the observations. As a consequence the model should be useful in ocean models with a sea ice component. Some of the implications for such modeling can be seen to be nontrivial from the large net heat fluxes out of the ocean predicted by the present model 
(a)

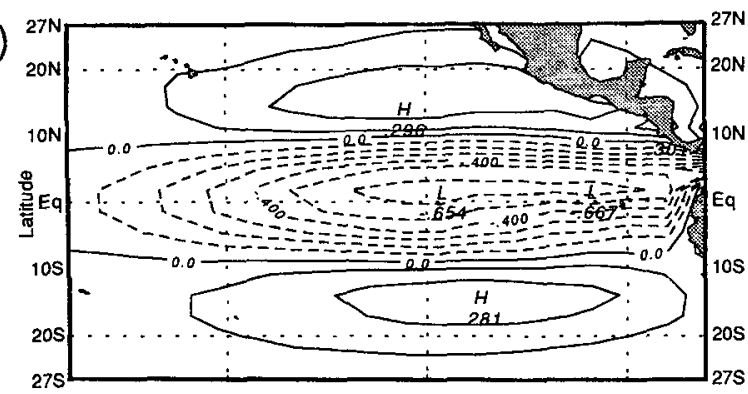

(b)

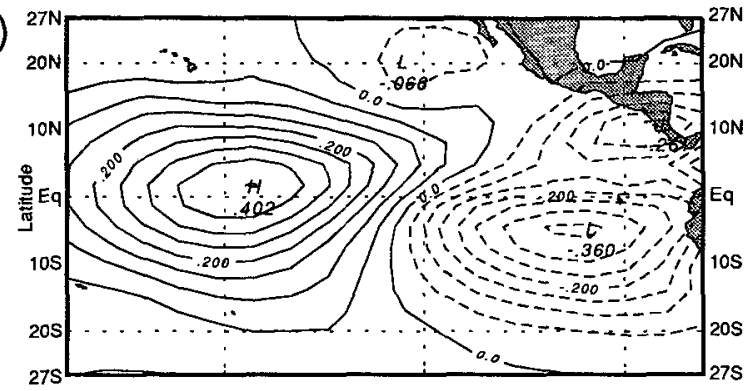

(c)

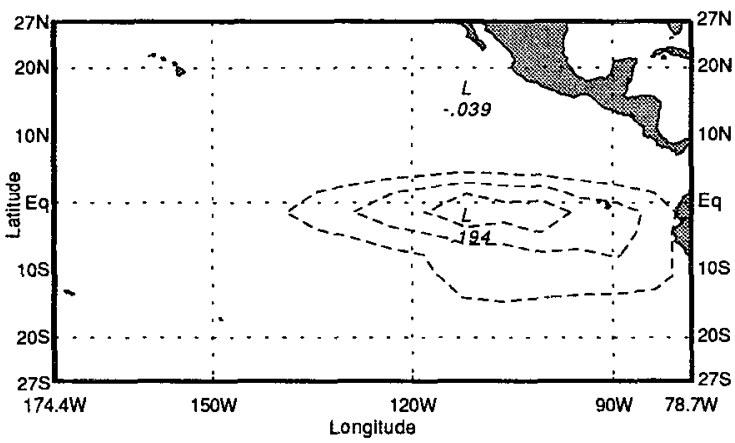

FIG. 11. (a) The change in the eddy diffusion tendency for air temperature in response to the SST anomaly of Fig. 9a. Contour interval is $0.1^{\circ} \mathrm{C} \mathrm{day}^{-1}$. (b) The change in the horizontal advection tendency for air temperature in response to the SST anomaly of Figure $9 \mathrm{a}$. Contour interval is $0.05^{\circ} \mathrm{C} \mathrm{day}^{-1}$. (c) The change in the vertical advection tendency for air temperature in response to the SST anomaly of Fig. 9a. Contour interval is $0.05^{\circ} \mathrm{C}_{\text {day }}{ }^{-1}$.

in the vicinity of sea ice. Examination of the temperature budget in these regions reveals that the large fluxes are a consequence of the transport of very cold air off the sea-ice packs.

Gleckler et al. (1994) have recently advocated examining the implied meridional heat transport of atmospheric models as a crude measure of how the model will perform when coupled to an ocean model. These authors find that many AGCMs have the incorrect transport in the Southern Hemisphere and they suggest that this may be a significant cause of the large climate drift often observed in coupled GCMs. Displayed in Fig. 13 is this quantity for the present model. As can be seen, there is significant poleward transport in both hemispheres, in agreement with the observed estimates presented in Gleckler et al. The poleward transport is

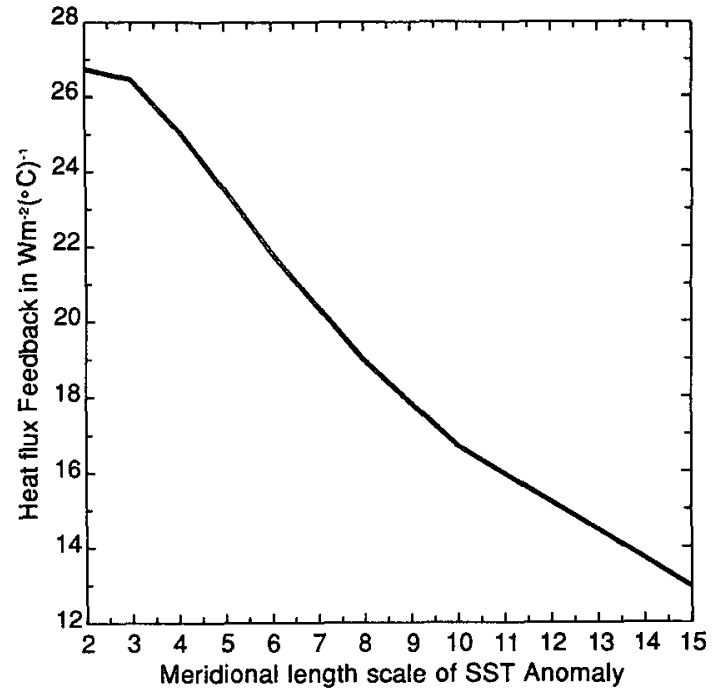

(Gaussian e-folding length)

FIG. 12. The equatorial net heat flux negative feedback for SST anomalies with varying meridional length scales.

perhaps too strong in the model at very low northern latitudes, but nevertheless the transport depicted suggests reasonable performance when the model is coupled to a global ocean model.

An interesting and novel feature of the present model is the importance of horizontal eddy diffusion (which parameterizes atmospheric transient eddy heat transport) in determining the oceanic surface net heat flux response. A study of the Gulf Stream net heat flux response showed it to be crucial in obtaining the correct spatial structure. In addition, an examination of the

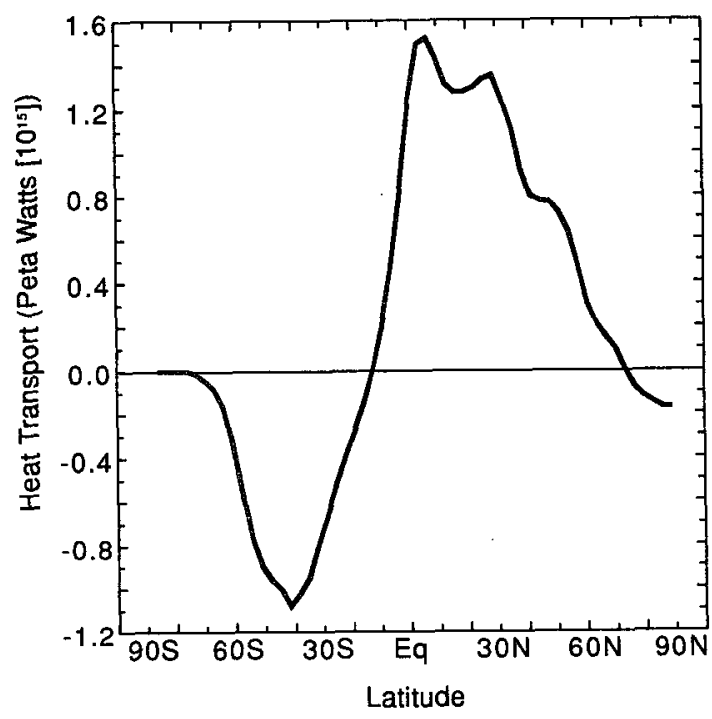

FIG. 13. The implied zonally averaged meridional ocean heat transport of the model. Units are in petawatts. 
model ENSO response reveals it to be very important to the negative feedback net heat flux response. Given that the diagnostic studies presented here also indicate that horizontal advection is significant, it would seem that both mechanisms should be included in future simple heat flux models.

The model developed here is intended to simulate the net heat flux response to small SST excursions from the current climate. It is important to realize the limitations of the model in doing this: Changes in (i) circulation, (ii) cloudiness, (iii) upper-air temperature, and (iv) land albedo are not included, so use of the current model without modeling these changes presumes that they are secondary to the changes in air temperature in their net heat flux implications. Of course, depending on the application envisaged, some of the changes could be incorporated by the use of other models. Thus, in the case of ENSO coupled modeling, there exist simple models giving good depictions of circulation and outgoing longwave radiation (OLR) changes (see Kleeman 1991) so that at least the first two changes detailed could be incorporated. Development of such a model is currently under way. This issue is probably important in modeling the North Atlantic as well since changes in the poleward gradient of SST induce changes in the midlatitude westerlies that will have net heat flux implications. A crude modeling of this effect was used in a different context by Power et al. (1994) and this could be used in conjunction with the present model.

The fixed upper-air temperature implies model limitations with regard to the vertical advection term since it remains unchanged in SST anomaly experiments. In general, the term is only climatologically significant in the subtropics adjacent to western continental margins ( these coincide closely, curiously enough, with major coastal upwelling zones). Omission of the term leads to cooler air temperatures in the tropical eastern Atlantic and Pacific Oceans and this leads to an erroneous decrease of around $25 \mathrm{~W} \mathrm{~m}^{-2}$ in the heat being pumped into the equatorial oceans. The restorative effect of the term can be seen in its influence on the idealized ENSO anomalies of the previous section. The air temperature anomaly is reduced as a result of its presence and hence the change in turbulent heat fluxes (the negative feedback heat flux effect) is enhanced. For the particular anomaly considered, this feedback effect is not large, as the horizontal transports tend to be a lot more efficient in this respect (cf. Fig. 11). For anomalies centered under the maximal subsidence (the coastal upwelling zones) calculation shows that vertical advection becomes important to the air temperature anomalies. The restorative influence of the term may be overdone since midtropospheric tropical temperature anomalies during ENSO tend to have the same sign as the SST anomalies they overlay (see CAC 1994).

Acknowledgments. Useful discussions with Dale Hess of BMRC; Jürgen Willebrand of the Institut für Meers- kunde, Kiel; Tony Hirst of CSIRO; and Nanne Weber of KNMI are gratefully acknowledged.

\section{REFERENCES}

Betts, A. K., and W. Ridgway, 1989: Climatic equilibrium of the atmospheric convective boundary layer over a tropical ocean. J. Atmos. Sci., 46, 2621-2641.

Bretherton, F. P., 1982: Ocean climate modeling. Progress in Oceanography, Vol. 11, Pergamon 93-129.

Bryan, K., and L. J. Lewis, 1979: A water mass model of the world ocean. J. Geophys. Rev., 84, 347-376.

Bunker, A. F., 1980: Trends of variables and energy fluxes over the Atlantic Ocean from 1948 to 1972. Mon. Wea. Rev., 108, 720732.

C.A.C., 1994: Climate Diagnostic Bulletin. September, 85 pp.

Dickinson, R. E., 1981: Convergence rate and stability of oceanatmosphere coupling schemes with a zero-dimensional climate model. J. Atmos. Sci., 38, 2112-2120.

- 1992: Land surface. Climate System Modeling. K. Trenberth, Ed., Cambridge University Press, $788 \mathrm{pp}$.

Garrett, J. R., 1992: The Atmospheric Boundary Layer. Cambridge University Press, $316 \mathrm{pp}$.

Gill, A. E., 1982: Atmosphere-Ocean Dynamics. Int. Geophys. Ser., Vol. 30, Academic Press, 662 pp.

Gleckler, P. J., D. A. Randall, R. Colman, V. Galin, W. Gough, A. Hollingworth, B. Hunt, A. Kitoh, W. Lau, B. J. McAvaney, K. Miyakoda, C.-K. Park, S. Planton, and W.-C. Wang, 1994: Interpretation of the meridional ocean energy transport implied by atmospheric general circulation models. Geophys. Res. Lett., in press.

Haney, R. L., 1971: Surface thermal boundary conditions for ocean circulation models. J. Phys. Oceanogr, 1, 241-248.

Hart, T. L., W. Bourke, B. J. McAvaney, B. J. Forgan, and J. L. McGregor, 1990: Atmospheric general circulation simulations with the BMRC Global Spectral Model: The impact of revised physical parameterizations. J. Climate, 3, 436-459.

Harvey, L. D. D., 1988: A semianalytic energy balance climate model with explicit sea ice and snow physics. J. Climate, 1, 922-927.

Holland, D. M., L. A. Mysak, D. K. Manak, and J. M. Oberhuber, 1993: Sensitivity study of a dynamic thermodynamic sea ice model. J. Geophys. Rev. (Oceans), 98, 2561-2586.

Hummel, J. R., and R. A. Reck, 1979: A global surface albedo model. J. Appl. Meteor., 18, 239-253.

Iqbal, M., 1983: An Introduction to Solar Radiation. Academic Press, $390 \mathrm{pp}$.

Kleeman, R., 1991: A simple model of the atmospheric response to ENSO sea surface temperature anomalies. J. Atmos. Sci., 48, 3-18.

- B. J. McAvaney, and R. C. Balgovind, 1993: An analysis of the interannual heat flux response in an atmospheric general circulation model. J. Geophys. Rev. (Atmos.), 99, 5539-5550.

Latif, M., 1987: Tropical ocean circulation experiments. J. Phys. Oceanogr., 17, 246-263.

Luksch, U., and H. von Storch, 1992: Modeling the low-frequency sea surface temperature variability in the North Pacific. J. Climate, 5, 893-906.

Manabe, S., and R. F. Strickler, 1964: Thermal equilibrium of the atmosphere with a convective adjustment. J. Atmos. Sci., 31, $361-385$.

Moore, A. M., and H. B. Gordon, 1994: An investigation of climate drift in a coupled atmosphere-ocean-sea ice model. Climate Dyn., in press.

Oberhuber, J. M., 1988: An atlas based on the COADS dataset: The budgets of heat, buoyancy, and turbulent kinetic energy at the surface of the global ocean. Max Planck Institut für Meteorologie Report No. 15. [Available from Max Planck-Institut, Bundesstraße 55, D-2000 Hamburg 13, Germany.]

Paltridge, G. W., and C. M. R. Platt, 1976: Radiative processes in meteorology and climatology. Elsevier, $318 \mathrm{pp}$. 
Philander, S. G. H., and A. D. Siegal, 1985: Simulation of the El Niño of 1982-83. Coupled Ocean-Atmosphere Models, Vol. 40, Elsevier, 517-541.

Power, S. B., and R. Kleeman, 1993a: Multiple equilibria in a global general circulation model. J. Phys. Oceanogr., 23, 1670-1681.

- , and - 1994: Surface heat flux parameterization and the response of ocean general circulation models to high latitude freshening. Tellus $B, 46 \mathrm{~A}, 86-95$.

- A. M. Moore, D. A. Post, N. R. Smith, and R. Kleeman, 1994: Stability of North Atlantic deep water formation in a global general circulation model. J. Phys. Oceanogr., 24, 904-916.

Rahmstorf, S., and J. Willebrand, 1994: The role of temperature feedback in stabilizing the thermohaline circulation. J. Phys. Oceanogr., 24, in press.

Reynolds, R. W., 1988: A real-time global sea surface temperature analysis. J. Climate, 1, 75-86.

Riehl, H., 1979: Climate and Weather in the Tropics. Academic Press, $611 \mathrm{pp}$.

Rowntree, P. R., 1991: Atmospheric parameterization schemes for evaporation over land: Basic concept and climate modeling as- pects. Land Surface Evaporation, Measurement and Parameterization, T. J. Schmugge and J. Andre, Eds., Springer-Verlag, $424 \mathrm{pp}$.

Schopf, P. S., 1983: On equatorial waves and El Niño. Part II: Effects of air-sea thermal coupling. J. Phys. Oceanogr., 13, 1878-1893.

Sellers, W. D., 1969: A global climatic model based on the energy balance of the earth-atmosphere system. J. Appl. Meteor., 8, 392-400.

Stocker, T. F., D. G. Wright, and L. A. Mysak, 1992: A zonally averaged coupled ocean-atmosphere model for paleoclimatic studies. J. Climate, 5, 773-797.

Stull, R. B., 1988: An Introduction to Boundary Layer Meteorology. Kluwer Academic, $666 \mathrm{pp}$.

Woodruff, S. D., R. J. Slutz, R. L. Jenne, and P. M. Steurer, 1987: A Comprehensive Ocean-Atmosphere Data Set. Bull. Amer. Meteor. Soc., 68, 521-527.

Zhang, S., R. J. Greatbatch, and C. A. Lin, 1993: A reexamination of the polar halocline catastrophe and implications for coupled ocean-atmosphere modeling. J. Phys. Oceanogr., 23, 287-299. 